\title{
Sleep in children with asthma: results of the PIAMA study
}

\author{
Annette van Maanen*, Alet H. Wijga\#, Ulrike Gehring", Dirkje S. Postma+, Henriëtte \\ A. Smit ${ }^{\S}$, Frans J. Oort*, ${ }^{*}$ Roos Rodenburg**** and Anne Marie Meijer*
}

ABSTRACT: Children with asthma are thought to have impaired sleep quality and quantity. In this study, we investigated which of the many sleep aspects are associated with asthma.

Our sample consisted of 2529 children (aged 11 years) who participated in the Prevention and Incidence of Asthma and Mite Allergy (PIAMA) birth cohort study. Parents reported about asthma symptoms (wheezing, dyspnoea, prescription of inhaled corticosteroids and asthma diagnosis) and children reported about different aspects of sleep (bedtime, rise time, sleep quality and daytime sleepiness/tiredness). Results were analysed with (logistic) regression analysis.

Children with frequent asthma symptoms significantly more often reported that they felt sleepy or tired during the day (34.4\% experienced daytime sleepiness/tiredness at least once a week) than children without asthma symptoms (22.2\%) and children with infrequent asthma symptoms (21.9\%). This association was not confounded by sex, age of the child, parental educational level or smoking inside the house; the effect was also not modified by sex. There were no associations between asthma and bedtime, time spent in bed or sleep quality.

Children with frequent asthma symptoms experienced daytime sleepiness/tiredness more often than children with infrequent or no asthma symptoms. Otherwise, children with asthma did not differ much from children without asthma with regard to sleep.

KEYWORDS: Childhood asthma, daytime sleepiness/tiredness, dyspnoea, wheezing

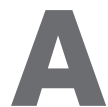

sthma is a chronic inflammatory airway disease and is considered the most prevalent chronic respiratory disorder in childhood [1]. Asthma seems to be a risk factor for disturbed sleep: asthma symptoms often worsen at night [2] and can cause sleep disruptions [1]. Sleep problems in turn have negative consequences for health [3], behaviour [4], cognitive functioning and school performance $[5,6]$. As children with asthma generally show more behavioural problems than children without asthma [7], it is important to gain more insight into sleep in childhood asthma.

Research into sleep in children with asthma has yielded contradictory results. On the one hand, several studies have shown that children with asthma wake up more often in the night [1, 8-11] and have worse sleep quality than healthy children [1, 8-10, 12]. On the other hand, other studies did not find that children with asthma have lower sleep quality or more disrupted sleep $[13,14]$. Asthma does not seem to influence sleep latency or sleep duration [8-10, 12, 14]. However, asthma appears to be consistently related to sleepiness or tiredness in children [1, 8, 9, 12, 15]. This may have important bearings on daytime activities and cognitive performance and, hence, school achievements [16].

In addition, it was found that persistent wheezing [17], more severe asthma [12, 16, 18] and uncontrolled asthma [19] were associated with worse sleep. These findings may partly explain the contradictory results described above. It is possible that well-controlled asthma does not affect sleep, but sleep is negatively affected in the case of more serious symptoms or in uncontrolled asthma. As most studies investigated only one or a few sleep aspects (most often night-time awakenings) and used different definitions of asthma, it is difficult to draw firm conclusions about whether asthma affects sleep.

In the present study, we investigated sleep in different groups of children with asthma, based on the frequency of their symptoms. First, to investigate the most essential aspects of sleep, we examined bedtime, a prominent feature of sleep in children. Secondly, we investigated time spent in bed as indicator of sleep duration and sleep latency, frequency of nocturnal awakenings, sleep latency after nocturnal awakenings and feeling fit at rise time as indicators of sleep quality.
AFFILIATIONS

*Research Institute of Child Development and Education, University of Amsterdam, Amsterdam,

"Centre for Prevention and Health Services Research, National Institute for Public Health and the Environment, Bilthoven, "Institute for Risk Assessment Sciences, Utrecht University, Utrecht, ${ }^{+}$Dept of Pulmonary Medicine and Tuberculosis, University Medical Centre Groningen, University of Groningen, GRIAC Research Institute, Groningen,

${ }^{\S} J u l i u s$ Centre for Health Sciences and Primary Care, University Medical Centre Utrecht, Utrecht, ${ }^{f}$ Dept of Medical Psychology, Academic Medical Centre, University of Amsterdam, Amsterdam, and

**Epilepsy Institute in the Netherlands Foundation, Heemstede, The Netherlands.

\section{CORRESPONDENCE}

A. van Maanen

Research Institute of Child Development and Education University of Amsterdam Nieuwe Prinsengracht 130 1018 VZ Amsterdam The Netherlands E-mail: A.vanMaanen@uva.n

Received: Jan 312012 Accepted after revision: June 302012 First published online: Aug 162012 
Sleep duration and sleep quality are considered two different sleep domains [20]. Finally, we assessed daytime sleepiness/ tiredness as one of the consequences of insufficient sleep duration and/or unsatisfying sleep quality. By using these different asthma phenotypes and investigating several sleep aspects in the same individuals, we aimed to clarify the contradictory results that are found in the literature on the relationship between childhood asthma and sleep.

We aimed to answer the following two research questions. 1) Are there differences in sleep between children with and without asthma? 2) Are there differences in sleep between children with frequent and infrequent asthma symptoms?

\section{METHODS}

\section{Study design and study population}

The study population consisted of children born in 1996-1997 who participated in the Prevention and Incidence of Asthma and Mite Allergy (PIAMA) birth cohort study. A detailed description of the study design has been published previously [21]. Briefly, pregnant females were recruited from the general population by means of a validated screening questionnaire on maternal allergy [22], distributed to the females when visiting a pre-natal clinic in the Netherlands. On the basis of this screening, 7862 females (2779 allergic mothers and 5083 nonallergic mothers) were invited to participate in the study. Approximately $50 \%$ of the invited pregnant females $(n=4146)$ agreed to participate. In the case of multiple births, only one of the children was included in the study. After birth, the baseline study population consisted of 3963 children. Questionnaires were sent to the participating parents during pregnancy, at 3 months, yearly from age 1 to 8 years, and at 11 years of age, around the child's birthday. At the age of 11 years, questionnaires were also completed by the children themselves. The present study reports on the 11-year questionnaires completed by parents and children and includes data on 2529 children for whom data on both asthma and sleep were available.

The study protocol was approved by the medical ethics committees of the participating research institutes, and all parents gave written informed consent.

\section{Measures}

\section{Asthma}

In all questionnaires from age 1 year onwards, the parents were asked to report whether the child had had an episode of wheezing, an episode of dyspnoea, or a prescription of inhaled corticosteroids for respiratory or lung problems during the last 12 months. In addition, parents were asked about the frequency of attacks during which wheezing or dyspnoea occurred. Additional questions were whether the child was ever-diagnosed with asthma by a doctor and whether the child had had asthma during the previous 12 months. Based on these questions, the following variables were defined and used in the present study. 1) Asthma symptoms were considered to be present when parents reported that their child had had one or more attacks of wheezing and/or one or more attacks of dyspnoea and/or a prescription of inhaled corticosteroids for respiratory or lung problems by a medical doctor during the last 12 months. If parents reported no wheeze, no dyspnoea and no prescription of inhaled corticosteroids, the child was defined as having no asthma symptoms. The group of children with asthma symptoms can be divided into children with frequent asthma symptoms and children with infrequent asthma symptoms, as follows. 2) Frequent asthma symptoms: parents reported that their child had had four or more attacks of wheezing and/or four or more attacks of dyspnoea during the last 12 months. 3) Infrequent asthma symptoms: parents reported asthma symptoms, but no frequent symptoms were reported. 4) Diagnosed asthma: parents reported that their child was everdiagnosed with asthma by a doctor and reported that their child had had asthma during the last 12 months.

\section{Sleep}

Children reported on bedtimes and rise times on both school and nonschool days; sleep latency (how long it takes to fall asleep after lights off), frequency of nocturnal awakenings, sleep latency after nocturnal awakenings, feeling fit at rise time (measures of sleep quality), and daytime sleepiness/tiredness ("Do you feel tired or sleepy during the day?"). Based on the child's report of their bedtimes and rise times, their time spent in bed was calculated.

\section{Confounding factors}

The following variables were tested for possible confounding influences: sex of the child, age of the child (exact age at the time that the questionnaire was completed); educational level of parents (highest attained educational level for mother and father separately); and smoking inside the house. The last two variables were considered indicators of lifestyle that might affect asthma and sleep [23-26].

\section{Statistical analysis}

Analyses were conducted with SPSS version 17 (SPSS Inc., Chicago, IL, USA). To investigate the associations between asthma and sleep, regression analyses were conducted with the different sleep items as dependent variables and binary indicators of asthma symptoms, frequent asthma symptoms or diagnosed asthma (defined according to the descriptions above) as independent variables. For the dependent variable with two response categories (feeling fit at rise time), logistic regression analyses was used; for dependent variables with three to five response categories (sleep latency, frequency of nocturnal awakenings, sleep latency after nocturnal awakenings and daytime sleepiness/tiredness) ordinal regression analyses were conducted; and for the dependent variables with nine (bedtimes) or more (time spent in bed) response categories regular linear regression analyses were conducted.

The influence of possible confounding variables was investigated by adding these as a covariate to the regression models. If, after addition of the covariate, the regression coefficient of asthma changed by $\geqslant 10 \%$ for several of the sleep outcomes, the covariate was considered to be a confounder.

To investigate whether the association between asthma and sleep differed for males and females, interaction effects between sex and asthma on the different sleep characteristics were examined. A significant interaction effect would indicate that the relationship between asthma and sleep was modified by sex (i.e. the relationship between asthma and sleep is different for males and females). 


\section{RESULTS}

At 11 years of age, 116 (4.6\%) children wheezed during the last year, 243 (9.6\%) children had dyspnoea and 169 (6.7\%) children had a prescription of inhaled corticosteroids. There were 317 $(12.6 \%)$ children with asthma symptoms, of whom 97 (3.9\%) had frequent symptoms and $220(8.7 \%)$ had infrequent symptoms. 100 (4.0\%) children had diagnosed asthma (table 1).

\section{Differences in sleep between children with and without asthma}

The mean time at which children went to bed and the mean time they spent in bed (difference between rise time and the time the lights were turned off) were not significantly different for children with asthma symptoms, children with frequent asthma symptoms (both compared with children without symptoms) or children with diagnosed asthma (compared with children who

\begin{tabular}{|c|c|}
\hline \multicolumn{2}{|c|}{ Description of the study population ${ }^{\#}$} \\
\hline Age years mean $\pm S D$ & $11.4 \pm 0.3$ \\
\hline Males & $1286(50.9)$ \\
\hline Asthma symptoms & $317(12.6)$ \\
\hline Frequent asthma symptoms & $97(3.9)$ \\
\hline Infrequent asthma symptoms & $220(8.7)$ \\
\hline $\begin{array}{l}\text { Diagnosed asthma (including asthma } \\
\text { during the previous } 12 \text { months) }\end{array}$ & $100(4.0)$ \\
\hline No asthma symptoms & $2202(87.4)$ \\
\hline \multicolumn{2}{|l|}{ Specific aspects of asthma } \\
\hline Wheezing during the last year & $116(4.6)$ \\
\hline Dyspnoea during the last year & $243(9.6)$ \\
\hline Corticosteroids & $169(6.7)$ \\
\hline Ever-diagnosed with asthma & $288(11.4)$ \\
\hline \multicolumn{2}{|l|}{ Sleep mean (SD min) } \\
\hline Bedtime school day & $20: 43 \mathrm{~h}(27.4)$ \\
\hline Bedtime not school day & $21: 41$ h $(39.7)$ \\
\hline Time in bed school day & 10:06 h (39.2) \\
\hline Time in bed nonschool day & $11: 23 \mathrm{~h}(55.0)$ \\
\hline \multicolumn{2}{|l|}{ Sleep latency } \\
\hline Fall asleep immediately & $619(24.5)$ \\
\hline Stay awake for a while & $1509(59.8)$ \\
\hline Takes a long time to fall asleep & $394(15.6)$ \\
\hline \multicolumn{2}{|l|}{ Nocturnal awakenings } \\
\hline (Almost) never & $1324(52.5)$ \\
\hline Sometimes & $1090(43.2)$ \\
\hline (Almost) every night & $110(4.4)$ \\
\hline \multicolumn{2}{|l|}{ Sleep latency after nocturnal awakenings } \\
\hline Mostly fall asleep immediately & $615(51.3)$ \\
\hline Mostly awake for a while & $488(40.7)$ \\
\hline Mostly takes a long time to fall asleep & $96(8.0)$ \\
\hline \multicolumn{2}{|l|}{ Feeling fit at rise time school day } \\
\hline Yes & $2061(82.0)$ \\
\hline No & $452(18.0)$ \\
\hline \multicolumn{2}{|l|}{ Daytime sleepiness/tiredness } \\
\hline (Almost) never & $1069(42.4)$ \\
\hline$<1$ per week & $880(34.9)$ \\
\hline \pm 1 per week & $282(11.2)$ \\
\hline \pm 2 per week & $165(6.5)$ \\
\hline$\geqslant 3$ per week & $124(4.9)$ \\
\hline
\end{tabular}

Data are presented as $n(\%)$, unless otherwise stated. ${ }^{*}: \mathrm{n}=2529$. do not meet the criteria for diagnosed asthma). When examining the results for daytime sleepiness/tiredness and sleep quality, a significant association was found only between children with frequent asthma symptoms and without symptoms on daytime sleepiness/tiredness. Children with frequent asthma symptoms significantly more often reported that they felt sleepy or tired during the day than children without asthma symptoms (table 2). There was a trend in the same direction for children with asthma symptoms (frequent and infrequent symptoms taken together) and children with diagnosed asthma. Children with asthma symptoms more often felt sleepy or tired during the day than children without asthma symptoms (of the children with asthma symptoms, $25.7 \%$ experienced daytime sleepiness/tiredness at least once a week versus $22.2 \%$ of children without symptoms). Children with diagnosed asthma indicated more often that they felt sleepy or tired during the day when compared with children who do not meet the criteria for diagnosed asthma (30.0\% versus $22.4 \%$ of children in the respective groups experienced daytime sleepiness/tiredness at least once a week), yet these associations did not reach significance ( $p=0.06$ and $p=0.11$; data not shown). Only results of the analysis comparing children with frequent asthma symptoms and children without symptoms are reported in the table.

Addition of sex, age of the child, educational levels of parents and smoking inside the house as covariates to the regression models changed the effect estimates for the associations with several of the sleep characteristics, but had little influence on the association between frequent asthma symptoms and daytime sleepiness/tiredness. In table 2, the results of both the crude and the adjusted analyses are shown. Next, we investigated interaction effects between asthma and sex to determine whether the associations between asthma and sleep differed for males and females. As no significant interaction effects were found, it appears that the relationship between asthma and sleep is not modified by sex.

\section{Differences in sleep between children with frequent and infrequent asthma symptoms}

Ordinal regression analysis showed a significant effect on daytime sleepiness/tiredness when comparing children with frequent and infrequent asthma symptoms (table 2). Children with frequent asthma symptoms significantly more often reported feeling sleepy or tired during the day than children with infrequent asthma symptoms. There were no significant associations between frequent asthma symptoms as compared with infrequent asthma symptoms and other sleep outcomes.

\section{DISCUSSION}

Children with frequent asthma symptoms experienced more daytime sleepiness/tiredness than children without asthma symptoms and children with infrequent asthma symptoms. This association was not confounded by sex, age, educational level of parents or smoking inside the house, and was not modified by sex. There were no associations between asthma and bedtime, time spent in bed or sleep quality.

Nocturnal awakening frequently occurs in asthma [1, 8-11, 16]; however, no effect of asthma on nocturnal awakenings was found in our study. We did find that $46.9 \%$ of the children with frequent asthma symptoms sometimes had nocturnal awakenings and 5.2\% (almost) always experienced awakenings during 
TABLE 2 Effects of asthma on sleep characteristics ${ }^{\#}$

\begin{tabular}{|c|c|c|c|c|c|c|}
\hline & $\begin{array}{l}\text { No asthma } \\
\text { symptoms }\end{array}$ & $\begin{array}{l}\text { Infrequent asthma } \\
\text { symptoms }\end{array}$ & $\begin{array}{l}\text { Frequent asthma } \\
\text { symptoms }\end{array}$ & $\beta(95 \% \mathrm{Cl})$ & $\beta(95 \% \mathrm{Cl})^{\circ}$ & p-value ${ }^{+}$ \\
\hline Subjects $n$ & 2202 & 220 & 97 & & & \\
\hline $\begin{array}{l}\text { Bedtime school days } \\
\text { mean (sD min) }\end{array}$ & $20: 44$ h (27.4) & $20: 42$ h (27.3) & $20: 42$ h $(27.7)$ & $-1.22(-6.80-4.36)$ & $-1.60(-7.13-3.92)$ & 0.57 \\
\hline $\begin{array}{l}\text { Bedtime nonschool days } \\
\text { mean (sD min) }\end{array}$ & $21: 42$ h (39.8) & $21: 39$ h (37.0) & $21: 40$ h (44.0) & $-1.34(-9.53-6.84)$ & $-0.81(-8.88-7.26)$ & 0.84 \\
\hline $\begin{array}{l}\text { Time in bed school days } \\
\text { mean (sD min) }\end{array}$ & 10:06 h (38.9) & $10: 03 \mathrm{~h}(45.0)$ & $10: 08 \mathrm{~h}(33.1)$ & $1.20(-6.66-9.06)$ & $2.27(-5.54-10.07)$ & 0.57 \\
\hline $\begin{array}{l}\text { Time in bed nonschool days } \\
\text { mean (sD } \mathrm{min} \text { ) }\end{array}$ & $11: 23 \mathrm{~h}(55.1)$ & $11: 17$ h (54.9) & $11: 29$ h (54.5) & $6.16(-5.04-17.36)$ & $8.64(-2.28-19.56)$ & 0.12 \\
\hline \multicolumn{7}{|l|}{ Sleep latency } \\
\hline Fall asleep immediately & $540(24.6)$ & $58(26.5)$ & $20(20.6)$ & $0.26(-0.15-0.66)$ & $0.28(-0.13-0.68)$ & 0.18 \\
\hline Stay awake for a while & $1318(60.0)$ & $127(58.0)$ & $58(59.8)$ & & & \\
\hline $\begin{array}{l}\text { Takes a long time to fall } \\
\text { asleep }\end{array}$ & $338(15.4)$ & $34(15.5)$ & 19 (19.6) & & & \\
\hline \multicolumn{7}{|l|}{ Nocturnal awakenings } \\
\hline (Almost) never & $1168(53.1)$ & $105(47.9)$ & $46(47.9)$ & $0.21(-0.19-0.61)$ & $0.25(-0.15-0.65)$ & 0.23 \\
\hline Sometimes & $940(42.7)$ & $101(46.1)$ & $45(46.9)$ & & & \\
\hline (Almost) every night & $91(4.1)$ & $13(5.9)$ & $5(5.2)$ & & & \\
\hline \multicolumn{7}{|l|}{$\begin{array}{l}\text { Sleep latency after nocturnal } \\
\text { awakenings }\end{array}$} \\
\hline $\begin{array}{l}\text { Mostly fall asleep } \\
\text { immediately }\end{array}$ & $536(52.0)$ & $56(49.1)$ & $21(42.0)$ & $0.35(-0.20-0.89)$ & $0.35(-0.20-0.90)$ & 0.21 \\
\hline Mostly awake for a while & $416(40.4)$ & $45(39.5)$ & $25(50.0)$ & & & \\
\hline $\begin{array}{l}\text { Mostly takes a long time } \\
\text { to fall asleep }\end{array}$ & $78(7.6)$ & $13(11.4)$ & $4(8.0)$ & & & \\
\hline \multicolumn{7}{|l|}{$\begin{array}{l}\text { Feeling fit at rise time school } \\
\text { day }\end{array}$} \\
\hline Yes & $1803(82.3)$ & $171(78.1)$ & $78(83.0)$ & $1.05^{\S}(0.60-1.81)$ & $1.00^{\S}(0.58-1.73)$ & $>0.99$ \\
\hline No & $387(17.7)$ & $48(21.9)$ & $16(17.0)$ & & & \\
\hline \multicolumn{7}{|l|}{$\begin{array}{l}\text { Daytime sleepiness/ } \\
\text { tiredness }\end{array}$} \\
\hline (Almost) never & $943(43.0)$ & $92(42.0)$ & $28(29.2)$ & $0.58(0.21-0.95)$ & $0.63(0.26-1.00)$ & $<0.01$ \\
\hline$<1$ per week & $764(34.8)$ & 79 (36.1) & 35 (36.5) & & & \\
\hline \pm 1 per week & $244(11.1)$ & $20(9.1)$ & $17(17.7)$ & & & \\
\hline \pm 2 per week & $140(6.4)$ & $16(7.3)$ & $9(9.4)$ & & & \\
\hline$\geqslant 3$ per week & $104(4.7)$ & $12(5.5)$ & 7 (7.3) & & & \\
\hline
\end{tabular}

Data are presented as $\mathrm{n}(\%)$, unless otherwise stated. For sleep latency, nocturnal awakenings, sleep latency after nocturnal awakenings and daytime sleepiness/ tiredness the results of ordinal regression analyses are reported. ${ }^{*}$ : regression coefficients are shown for children with frequent asthma symptoms compared with children

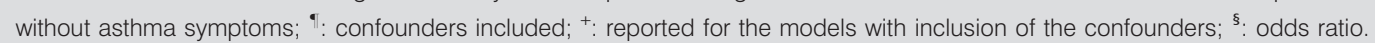

the night. However, our results showed that nocturnal awakenings also occurred in children without asthma symptoms and the difference between these groups was not statistically significant. It might be that the question on nocturnal awakenings was not sensitive enough to find an effect, as children could only choose from three response categories ((almost) never, sometimes and (almost) every night).

As we did not find differences for any of the other sleep variables, we cannot give a straightforward interpretation for the finding of increased daytime sleepiness/tiredness in children with frequent asthma symptoms compared with children with infrequent or without asthma symptoms. However, it could be that children with frequent asthma symptoms are more sleepy or tired during the day, partly because they have worse sleep quality (they have lower scores on most indicators of sleep quality, although not significantly worse), and partly because normal daytime activities are more tiring for them due to their asthma complaints. In addition, children with frequent asthma symptoms might become more sleepy or tired during the day than other children not only because of their asthma complaints, but also because of possible emotional/behavioural problems, which are more pronounced in children with asthma [7].

We found significant associations between asthma and sleep to be present only in children with frequent asthma symptoms. This result is in accordance with earlier studies that also found a 
relationship between severity of asthma and the extent to which sleep was impaired [12,16-19]. This indicates that an impact on sleep is evident only when asthma is not well controlled.

A possible explanation for the fact that we did not find associations between diagnosed asthma and any of the sleep characteristics could be that $77.0 \%$ of the children with diagnosed asthma had a prescription of inhaled corticosteroids, which has probably reduced nocturnal symptoms [27, 28]. Almost half $(48 \%)$ of the children with diagnosed asthma had only infrequent symptoms. Although also $56.7 \%$ of all children with frequent asthma symptoms had a prescription of inhaled corticosteroids, still all children in this group had four or more attacks of dyspnoea and/or four or more attacks of wheezing in the last 12 months. Thus, this group does not include children who are symptom free because of their treatment. The fact that only about half of the children in the group with diagnosed asthma had frequent symptoms is likely to be the result of adequate treatment and may also explain why we observed no associations between diagnosed asthma and sleep.

In our study, parents reported about asthma symptoms and children reported about their sleep. We used questionnaires to measure sleep, which enabled us to assess a wide range of different aspects of sleep, including factors like "feeling fit at rise time" and "daytime sleepiness/tiredness". However, we cannot exclude the possibility that self-reporting may have resulted in some misclassification of, for example, sleep duration. Use of objective measures (e.g. actigraphy) in addition to subjective measures might have been useful to support the findings. However, although actigraphy data are reported to be reliable and valid, they appear to have a low specificity in detecting wakefulness within sleep periods [29]. Although it is suggested that parents might underestimate the sleep problems of their children [30], there are studies, for example, that reported by DESAGER et al. [8], that have found relationships between asthma and sleep using parent reporting. Therefore, it would be advisable to include parental and child reporting about sleep in one study to enable comparison of results.

Our study offers a careful consideration on the association between asthma (using different phenotypes) and important sleep characteristics in a large sample of children. The results of our study provide support for the idea described in the introduction, that the severity or frequency of symptoms is an important factor influencing the relationship between asthma and sleep.

\section{Conclusion}

Our study found a difference in daytime sleepiness/tiredness between children with frequent asthma symptoms and children with infrequent symptoms or without symptoms. No differences on bedtime, time spent in bed or sleep quality were found. It can be concluded that children with asthma do not differ much from children without asthma with regard to sleep. However, we recommend that physicians pay attention to sleep in children with frequent asthma symptoms, considering the negative effects of daytime sleepiness/tiredness on behaviour, mood, cognitive functioning and school achievements of these children [3-6].

\section{SUPPORT STATEMENT}

Research relating to this manuscript was supported by The Netherlands Organization for Health Research and Development; The Netherlands Organization for Scientific Research; The Netherlands Asthma Fund, The Netherlands Ministry of Spatial Planning Housing, and the Environment; and The Netherlands Ministry of Health, Welfare and Sport.

\section{STATEMENT OF INTEREST}

Conflict of interest information can be found alongside the online version of this article at www.erj.ersjournals.com

\section{REFERENCES}

1 Chugh IM, Khanna P, Shah A. Nocturnal symptoms and sleep disturbances in clinically stable asthmatic children. Asian Pac J Allergy Immunol 2006; 24: 135-142.

2 Bentur L, Beck R, Irving CS, et al. Nocturnal wheeze measurement in young asthmatics. Pediatr Asthma Allergy Immunol 2004; 17: 191-197.

3 Roberts RE, Roberts CR, Duong HT. Chronic insomnia and its negative consequences for health and functioning of adolescents: a 12-month prospective study. J Adolesc Health 2008; 42: 294-302.

4 Meijer AM, Reitz E, Deković M, et al. Longitudinal relations between sleep quality, time in bed and adolescent problem behaviour. J Child Psychol Psychiatry 2010; 51: 1278-1286.

5 Diette GB, Markson L, Skinner EA, et al. Nocturnal asthma in children affects school attendance, school performance, and parents' work attendance. Arch Pediatr Adolesc Med 2000; 154: 923-928.

6 Meijer AM. Chronic sleep reduction, functioning at school and school achievement in preadolescents. J Sleep Res 2008; 17: 395-405.

7 McQuaid EL, Kopel SJ, Nassau JH. Behavioral adjustment in children with asthma: a meta-analysis. J Dev Behav Pediatr 2001; 22: 430-439.

8 Desager KN, Nelen V, Weyler JJJ, et al. Sleep disturbance and daytime symptoms in wheezing school-aged children. J Sleep Res 2005; 14: 77-82.

9 Stores G, Ellis AJ, Wiggs L, et al. Sleep and psychological disturbance in nocturnal asthma. Arch Dis Child 1998; 78: 413-419.

10 Verhulst SL, Vekemans K, Ho E, et al. Is wheezing associated with decreased sleep quality in Sri Lankan children? A questionnaire study. Pediatr Pulmonol 2007; 42: 579-583.

11 Yeatts KB, Shy CM. Prevalence and consequences of asthma and wheezing in African-American and white adolescents. J Adolesc Health 2001; 29: 314-319.

12 Sadeh A, Horowitz I, Wolach-Benodis L, et al. Sleep and pulmonary function in children with well-controlled, stable asthma. Sleep 1998; 21: 379-384.

13 Ronchetti R, Villa MP, Matricardi PM, et al. Association of asthma with extra-respiratory symptoms in schoolchildren: two crosssectional studies 6 years apart. Pediatr Allergy Immunol 2002; 13: 113-118.

14 Tirosh E, Scher A, Sadeh A, et al. Sleep characteristics of asthmatics in the first four years of life: a comparative study. Arch Dis Child 1993; 68: 481-483.

15 Calhoun SL, Vgontzas AN, Fernandez-Mendoza J, et al. Prevalence and risk factors of excessive daytime sleepiness in a community sample of young children: the role of obesity, asthma, anxiety/ depression, and sleep. Sleep 2011; 34: 503-507.

16 Meijer GG, Postma DS, Wempe JB, et al. Frequency of nocturnal symptoms in asthmatic children attending a hospital out-patient clinic. Eur Respir J 1995; 8: 2076-2080.

17 Rona RJ, Li L, Gulliford MC, et al. Disturbed sleep: effects of sociocultural factors and illness. Arch Dis Child 1998; 78: 20-25. 
18 Strunk RC, Sternberg AL, Bacharier LB, et al., Nocturnal awakening caused by asthma in children with mild-to-moderate asthma in the Childhood Asthma Management Program. J Allergy Clin Immunol 2002; 110: 395-403.

19 Dean BB, Calimlim BC, Sacco P, et al. Uncontrolled asthma among children: impairment in social functioning and sleep. J Asthma 2010; 47: 539-544.

20 Pilcher JJ, Ginter DR, Sadowsky B. Sleep quality versus sleep quantity: relationships between sleep and measures of health, well-being and sleepiness in college students. J Psychosom Res 1997; 42: 583-596.

21 Brunekreef B, Smit J, de Jongste J, et al. The prevention and incidence of asthma and mite allergy (PIAMA) birth cohort study: design and first results. Pediatr Allergy Immunol 2002; 13: 55-60.

22 Lakwijk N, van Strien RT, Doekes G, et al. Validation of a screening questionnaire for atopy with serum $\operatorname{IgE}$ tests in a population of pregnant Dutch women. Clin Exp Allergy 1998; 28: 454-458.

23 de Meer G, Reijneveld SA, Brunekreef B. Wheeze in children: the impact of parental education on atopic and non-atopic symptoms. Pediatr Allergy Immunol 2010; 21: 823-830.
24 Pattenden S, Antova T, Neuberger M, et al. Parental smoking and children's respiratory health: independent effects of prenatal and postnatal exposure. Tob Control 2006; 15: 294-301.

25 O'Brien LM, Holbrook CR, Mervis CB, et al. Sleep and neurobehavioral characteristics of 5- to 7-year-old children with parentally reported symptoms of attention-deficit/hyperactivity disorder. Pediatrics 2002; 111: 554-563.

26 Sadeh A, Raviv A, Gruber R. Sleep patterns and sleep disruptions in school-age children. Dev Psychol 2000; 36: 291-301.

27 Weersink EJM, Douma RR, Postma DS, et al. Fluticasone propionate, salmeterol xinafoate, and their combination in the treatment of nocturnal asthma. Am J Respir Crit Care Med 1997; 155: 1241-1246.

28 Wempe JB, Tammeling EP, Postma DS, et al. Effects of budesonide and bambuterol on circadian variation of airway responsiveness and nocturnal symptoms of asthma. J Allergy Clin Immunol 1992; 90: 349-357.

29 Sadeh A. The role and validity of actigraphy in sleep medicine: an update. Sleep Med Rev 2011; 15: 259-267.

30 Fricke-Oerkermann L, Plück J, Schredl M, et al. Prevalence and course of sleep problems in childhood. Sleep 2007; 30: 1371-1377. 